\title{
The contribution of demographic and health survey data to population and health policymaking: evidence from three developing countries
}

\author{
Laura B. Nolan ${ }^{1}$, Rachel Lucas ${ }^{2}$, Yoonjoung $\mathrm{Choi}^{3}$, Madeleine Short Fabic ${ }^{4}$ \& Jacob \\ Adetunji $^{4}$ \\ ${ }^{1}$ Mathematica Policy Research, Oakland, CA, USA \\ ${ }^{2}$ Office of HIV/AIDS, U.S. Agency for International Development, Washington, DC, USA \\ ${ }^{3}$ Department of Population, Family, and Reproductive Health, Johns Hopkins University, Baltimore, \\ MD, USA \\ ${ }^{4}$ Office of Population and Reproductive Health, U.S. Agency for International Development, \\ Washington, DC, USA
}

LNolan@mathematica-mpr.com

\begin{abstract}
This paper investigates how and why DHS data were used in select health policy decision-making processes and how best the use of evidence can be supported in future. We use data from in-depth interviews with 22 professionals working in health and policy think-tanks, government agencies, foundations, survey research, and non-government organizations. We undertake a cross-case thematic analysis of the interview content and available documents to develop three case studies (Malawi, India, and Rwanda) of evidence-based policymaking. These case studies outline the way in which DHS data were used in a variety of policymaking contexts and how it facilitated policymakers' appreciation of the scope of problems, highlighted mismatch between population health needs and service provision, supported advocacy efforts, provided concise and compelling issue framing, and catalyzed high-level political commitments. The paper presents a framework that can be used to understand the use of evidence in health policy decision-making in developing countries.
\end{abstract}

Keywords: Health policy, population health, survey data, developing countries

\section{Introduction}

Reducing poverty and accelerating development in low- and middle-income countries requires equitable, efficient and informed public policy. While public health policy, in the form of laws, regulations, and guidelines, can significantly improve population health (Brownson et al. 2009), health policy based on evidence "provides a foundation on which to build strong health systems, programs and services" (Futures Group 20l0). The use of evidence in policymaking can produce more informed decisions (Segone and Pron 2008), improve policymakers' confidence in the decisions they make (Campbell et al. 2007) and increase the relevance, efficiency, and efficacy of public service delivery (Sutcliff and Court 2005). Successfully supporting the use of evidence in the formulation of health policy requires both a comprehensive understanding of the policy-making process, and an awareness of the strategic entry points at which data may be utilized (Moat and Lavis 2013).

Policy analysis, or "the study of the processes through which ideas, knowledge, interests, power and institutions influence decision-making...[paying] particular attention to how problems are defined, agendas are set, policy is formulated and reformulated, implemented and evaluated" (Parsons, 1995) can help policymakers, researchers and civil society understand failures and successes of the past, and plan policy-related activities in the future (Walt et al. 2008). Analyses of past successes such as those undertaken in this paper - the methods, stakeholders, inputs, and processes most often present when data are successfully put to good use in the health policy arena - can help inform and facilitate future integration of health in the policy process (Morgan 2010). In public health, it is well known that "good data will lead to better decisions, which will result in enhanced population health," (AbouZahr et al. 2007) suggesting that increased use of reliable, generalizable, credible, objective and contextualized (Shaxson 2006) evidence will likely improve upon the current efficiency and effectiveness of health policy. While evidence is increasingly used in the policy process (Behague et al. 2009), its integration has only been minimally investigated by researchers undertaking policy analyses. A small 
number of peer reviewed articles and reports have investigated the link between research and policy in developed countries on topics in health (Laws et al. 20I3), education (Birhaum 2000), and international relations (Milani 2005), among other policy spheres. However, an even smaller number of articles focus mainly on the link between health-related data and health policy in developing countries (Jiang et al 2013, Philpott et al. 2002), and this body of literature has been described as "small, diverse, fragmented and quite descriptive in nature" (Gilson and Raphaely 2008).

In order to contribute to the empirical evidence base on health policy analysis in low- and middleincome countries, we employ a case study methodology to explore data from the Demographic and Health Surveys (DHS) as one input into the policy process, highlighting specific points at which the use of data is most effective. While evidence can be quantitative or qualitative in nature, coming from sources as diverse as administrative records, Censuses, randomized controlled trials, household surveys including biometric and self-reported data, demographic surveillance sites, projects run by multilateral, non-governmental and religious organizations, and individual researchers, to name a few, we focus on DHS data in particular because these data: I) Are often the only reliable nationally representative data available on population and health indicators in resource-constrained settings with weak or nonexistent vital registration and other information systems, 2) Are uniform across countries and therefore allow investigation of their use across multiple contexts, 3) Are nationally representative and therefore applicable to national-level policymaking, 4) Are collected frequently and therefore lend themselves to both policy formulation and evaluation, 5) Are generally of high quality (Clemens and Demombynes 2013), which is a necessary prerequisite for their use (Shaxson 2006, Lewin et al. 2012), and 6) Are increasingly employed in peer-reviewed publications on health issues, a testament to their accessibility and relevance for individuals concerned with health policy and systems (Short Fabic et al. 2012). Collecting these data is expensive and labor intensive, but to date there has been no formal investigation of whether and how the DHS have informed health policy in the countries in which they are collected. This study aims to fill that gap.

A variety of theoretical frameworks and models have been developed to facilitate the formal investigation of the use of evidence in health policymaking (Hanney et al. 2003). These include, but are not limited to, the knowledge-driven model in which evidence propels action in a linear sequence, the policy-driven model in which identification of an issue leads to requests for research, and the political model, whereby politicians use research findings to justify their actions (see Orem et al.2013, Rychetnik et al 2012, Hanney 2003) for reviews and Table I for a summary as described by Weiss (1979). With Walt's policy triangle as a guide, we investigate which of the frameworks described in Table I best reflects the use of DHS data in policymaking. We use a case study methodology to describe the policy process, or the way in which policies come about, are negotiated, communicated, implemented and/or evaluated (Walt and Gilson 1994, Buse and Mays 2005), in three instances of successful evidence-based health policy (EBHP) formulation. We follow the policy process through the development of policy content, which is embedded in the local political, economic and social/cultural context of the country and time period (Buse and Mays 2005). Our case study approach and cross-case analyses lead to the identification of points in the policy process at which survey data, DHS data in particular, are most helpful in facilitating evidencebased policy.

Given that this study is intended to investigate whether and how DHS data are used in evidencebased health policy and to provide a guide for planning a strategic approach to support its use, we ask the following two research questions: How, when and why are DHS data used in formulating and revising health policy in developing countries?; and what have been some of the most effective ways to support this process? The determination of cause and effect is not the goal of this exercise (Galea et al 20I0), rather these questions are intended to illuminate the integration of survey data in the policy process. EBHP is an essential foundation on which strong health systems, programs and services should be built to improve population health and spur development. By highlighting past successes, this study is intended to facilitate and strengthen future integration of evidence into health policy. More specifically, ours is the first formal study of the use of DHS data in the formulation of national health policy. We hope the findings will promote further integration of DHS and data more generally into decision-making in order to promote the efficiency and efficacy of health policy and services.

\section{Methods}

We focus our investigation on the use of Demographic and Health Survey (DHS) data. Begun in 1984 by the United States Agency for International Development (USAID), the DHS Program has provided technical assistance to more than 300 population-based surveys in 90 countries. The DHS Program provides technical assistance to survey 
implementing agencies - typically national statistical offices. The data are freely available, nationally representative, periodically collected (typically every five years), standardized across countries and time, and of high quality. For these reasons, DHS data have been increasingly incorporated into high-level decision-making processes as governments' prioritysetting and accountability procedures are scrutinized and strengthened (I0), and they strive to achieve the Millennium Development Goals (Boerma and Stansfield 2007). The use of DHS data thus provides fertile ground for case study.

The case study methodology employed here is particularly helpful for understanding "'how" and "why" questions...when the investigator has little control over events, and when the focus is on contemporary phenomenon within some real-life context" (Yin 2002), which describes the settings in which policy analyses are typically undertaken. Before beginning interviews, the first author (LBN) conducted a literature review of EBHP-related publications using search terms that included "evidence based health policy", "data and policy", or some combination thereof using PubMed, JSTOR, EBSCOhost, Google Scholar, and USAID's Development Experience Clearinghouse. Searches for literature more directly related to each of the cases were also performed across these same databases, using search terms specific to each case. The first author also conducted a review of DHS data available for each case study country using information available at dhsprogram.com (Table 2).

In June, 20II, LBN began with in-depth, semistructured interviews to identify potential case studies illustrating the successful use of survey data in health policymaking. Interviewees were selected based on their familiarity with the history, collection, and use of DHS data. Of the initial fifteen informants, eight were staff members from The DHS Program's contractor (ICFI), four were from USAID, and there was one respondent each from a think tank, a forprofit company, and a non-for profit company, respectively. Initial interviewees were asked to identify instances of health policy development, change, or implementation based on DHS data. They were also asked to provide the names of additional individuals who would be able to describe these instances in more detail, as well as written documentation of policy processes, if available.

A second set of interviews were conducted by the second author (RL) and LBN with purposively selected individuals $(\mathrm{n}=7)$ based on the recommendations of the initial interviewees. These interviewees were demographers and health policy experts based at internationally recognized institutions. The interviews were conducted between
June and August 2012. Both LBN and RL had previous experience conducting in-depth semistructured interviews; RL had received extensive training in rigorous qualitative research methodology. Interviews were not recorded, but thematic notes were kept by the interviewers and remain in their possession.

The second set of interviews was intended to investigate more thoroughly the six potential case studies that had been identified in the first set of interviews. These six case studies focused on a broad range of health-related topics, from breastfeeding in the Philippines to domestic violence in Moldova to increasing access to contraceptive methods in Kenya. Interviewees were asked about how the use of data became prioritized in the policy process and by whom, the content of relevant policy meetings and debates, and the chronology of events. They were also asked for insight into common elements of successful data use across the examples they offered. While efforts were made to identify local government and civil society stakeholders who participated directly in the events described in the case studies, connecting with these individuals via either email or phone was not possible due to the amount of time elapsed since the events took place as well as significant job churn. With this second round of interviews, it was found that the lessons from Kenya were broadly similar to those from Rwanda presented here, and that there was insufficiently detailed documentation of the policy process (apart from administrative orders and legislation) to present the case studies from Moldova and the Philippines. For these reasons, we present three of the original six case studies here.

In sum, a total of 22 interviews were conducted and three case studies (from Malawi, India, and Rwanda) were found to meet the following criteria: I) Adequate documentation and information was available to describe the policy process; 2) Adequate documentation and information was available to describe the role of survey data in the policy process; and 3) Policy outcomes were health related. All respondents approached agreed to participate, and after the researchers explained the purpose of the study and that interviewee's views on the matters discussed would be shared but their identities protected, all participants provided verbal consent. Given the focus of this study on the content and chronology of the policy process and not on the attributes of the interviewees themselves, IRB review was not required.

Table 3 presents the characteristics of "key informant" interviewees (cited hereafter as "Kl"s) whose input directly informed at least one of the three chosen case studies $(n=7)$ and "informant"

http://aps.journals.ac.za 
interviewees (cited hereafter as "I"s), whose input indirectly informed at least one of the three case studies $(n=15)$, such as by recommending other potential interviewees or providing information on the use of survey data in EBHP more generally. These two types of informants are separated by a grey line in Table 3.

We employed Yin's (2003) holistic multiple-case design approach in which "selecting...cases requires prior knowledge of the outcomes, with the multiplecase inquiry focusing on how and why the exemplary outcomes might have occurred" in order to investigate the successful use of evidence in the policy process. Using thematic analysis, the authors conducted a detailed review of interview notes and written documentation in order to draw out common themes and turning points in the narratives described in the chosen case studies. Identifying patterns across case studies (Yin 2003) allowed for the integration of "categories or themes into a unified theoretical explanation" (Corbin 2008), producing the conceptual model in Table 4. The six steps of this model are referenced at the end of each case study description to facilitate the summarization of the most important points in the policy process at which survey data were utilized. We use Yin's data-driven conceptual model to articulate points in the policy process at which information was utilized to drive decisions. The implications of these findings for widespread use of data in policy decision-making are presented in the discussion section.

\section{Results}

Malawi

Malawi is one of the fastest growing countries in Africa, with an annual population growth rate of 3 percent (Haub and Kent 2008). Over eighty percent of Malawi's population lives in rural areas and more than half of primary health care is provided by community-based paraprofessionals (Richardson et al. 2009). Although modern contraceptive prevalence among married women increased dramatically throughout the 1990s, from about 7 percent in 1992 to 26 percent in 2000 , by the mid-2000s both the total fertility rate (TFR) and the contraceptive prevalence rate (CPR) had stalled at about 6 births per women and 28 percent ( 35 percent in urban areas, 27 percent in rural areas), respectively (National Statistical Office and ORC Macro, 2005). The 2004 DHS showed that unmet need for family planning remained high, at nearly 28 percent.

To meet Malawian's reproductive health needs, community based distribution agents (CBDA) began providing family planning services in the late 1980s including oral contraceptives, condoms and referrals to family planning services. But Malawi DHS 2004 http://aps.journals.ac.za showed that 60 percent of married Malawian women preferred injectable contraceptives as their main method (National Statistical Office and ORC Macro, 2005), which the CBDA could not provide given injectable's classification as facility-based, prescription-only medicines to be administered by health professionals. But survey data clearly showed the simultaneous popularity of injectables and unmet need for contraception, which prompted the government of Malawi's Ministry of Health Reproductive Health Unit (RHU), and other incountry stakeholders (KI-I, $\mathrm{KI}-3)$, to explore expanding the availability of injectable contraceptives at the community-level. But the RHU met with significant resistance from medical and regulatory bodies, who were concerned that the level of training and supervision required would be inadequate for community-based distribution. They were also opposed to increasing CBDA's workload, which was already heavy ( $\mathrm{KI}-\mathrm{I}, \mathrm{KI}-2, \mathrm{KI}-3)$.

In 2007, a feasibility study was conducted of community based distribution (CBD) of injectable contraceptives through the existing network of Health Surveillance Assistants (HSAs), a sub-set of CBDAs who were a salaried cadre in Malawi's public health system. The study found that rural women and service providers actually preferred HSAs to administer injectable contraceptives in the community, rather than limiting access to health facilities (Richardson et al. 2009). With the feasibility study as catalyst, and under the resourceful leadership of their Director, the RHU resolved to advocate for HSAs to be able to provide injectable contraceptives at the community level in order to respond to the demand $(\mathrm{KI}-3)$.

The RHU Director and his staff compiled the DHS data, findings from the feasibility study, and the results of a literature review on CBD of injectables, and presented their proposal to Ministry of Health $(\mathrm{MOH})$ Senior Management, among other stakeholders (KI-2). In his presentation, the Director emphasized the MOH's vision, laid out in the Reproductive Health Strategy (2006-2010), part of which was to reduce the TFR from 6 to 4.9 births per woman and increase the CPR from 28 percent to 40 percent by 2010 . He reminded his audience of the evidence pointing to a large and growing demand for injectable contraceptives among Malawian women, and presented additional evidence on the safety of paraprofessional administration of injectables already occurring in other countries (KI-2) (Malaecher 2009). After much debate, on March 14, 2008 the MOH Senior Management Team decided to allow HSAs to administer injectable contraceptives in a phased-in approach. Following this decision, $\mathrm{MOH}$ staff and other key partners traveled to Madagascar to 
observe community-based volunteers - whose qualifications were less than those of Malawi's HSAs successfully administer injectable contraceptives (KI4). Soon after the conclusion of the study tour, the $\mathrm{RHU}$, with international technical support, organized a consensus building stakeholders' workshop where the survey data on contraceptive preferences and unmet need, feasibility study results, and lessons learned on the study tour were widely disseminated (KI-2, KI-3). All stakeholders committed to piloting CBD of injectable contraceptives by HSAs (Ministry of Health and Population 2008). Under the guidance of the RHU and with international funding and technical support, a pilot was implemented and subsequently expanded to the national level.

\section{Summary of contribution of evidence to the policy process:}

Malawi DHS 2004 indicated clear preferences for injectable contraceptives among Malawian women and high unmet need for contraception. This gap in public health service provision was highlighted to stakeholders, leading to their explicit recognition of the issue (step I in model described in Table 4). Using survey and other relevant data, the Director convincingly advocated for considering the expansion of women's choice and access to contraceptives through CBD of injectables (steps 2 and 3). The concerns of $\mathrm{MOH}$ Senior Management were met with additional evidence from the feasibility study and Madagascar study tour, which led to broad commitment (step 4). Malawi's efforts to act on evidence-based health needs (step 5) were rewarded when modern contraceptive use jumped to 58 percent among married women in 2014-20I5 (step 6) (National Statistical Office and ICF Macro 20I6).

\section{India}

AIDS was first detected in India in 1986, and some projections estimated that by 2010, 20 to 25 million Indians would be infected (Kates et al. 2006). To track its epidemic, India established the National AIDS Control Organization (NACO) in 1992. But for many years, NACO grappled with the accuracy of its prevalence estimates (Kadiyala and Barnett 2004), in part due to their being primarily based on HIV sentinel surveillance data from antenatal care clinics and other at-risk populations (Pandey et al. 2008). These non-representative samples of the Indian population were likely to produce overestimates of HIV prevalence (Cohen 2007). There was broad agreement that more accurate prevalence estimates were needed (KI-5). Not only would the accuracy of the data impact India's own response to its epidemic, but it would also impact the global health community's response. As the world's second most populous country, the accuracy of global HIV/AIDS estimates depended in large part on India's ability to produce good-quality national surveillance data.

In 2005-2006 the National Family and Health Survey (NFHS-3) included - for the first time - HIV testing of a representative sample of Indian adults, providing prevalence estimates for the population as a whole (Pandey et al. 2009). The results, which were disseminated in 2007, indicated that 0.28 percent of adults aged 15-49 were infected with HIV/AIDS in India, or approximately 1.707 million people (International Institute for Population Sceinces and Macro 2007). This was significantly lower than estimates presented by NACO in 2006 of 5.2 million Indian adults aged I5-49 (NACO 2006) and UNAIDS estimates at the end of 2005 of 3.9-9.4 million (UNAIDS 2006). Both sources had previously maintained that India had the largest number of people living with HIV than any other country in the world.

The NFHS-3 estimates generated heated international debate, and a storm of press coverage, including more than 275 newspaper articles, numerous TV broadcasts, radio spots, and internet articles (KI-6). The controversy prompted NACO to convene three Core Technical Working Group on HIV Estimates and Projections meetings in 2007, consisting of approximately 40 experts in HIV estimation. The group spent months discussing various ways to make use of all the available data the NFHS-3, sentinel surveillance, census data, and Integrated Biological and Behavioral Assessment data (which provided estimates of at-risk group size). Using a complex step-wise, state-by-state methodology, prevalence was first estimated for each state from the HIV sentinel surveillance sites and then calibrated to the NFHS-3 data (UNAIDS 2007); forecasting models were used to establish trends and uncertainty intervals (Pandey et al. 2008). The group's final estimates revised India's HIV/AIDS prevalence to 0.36 percent, or 2.5 million people (Chhabra 2008, Ghosh et al. 20I I).

Quality survey data vindicated policymakers, researchers, and practitioners who in 2004 had challenged a sweeping statement by the Executive Director of the Global Fund to Fight AIDS, Tuberculosis and Malaria, that India was "on an African Trajectory" (Rao et al. 2004). In fact, no generalized epidemic materialized; the majority of HIV infections in India remain concentrated in vulnerable populations like sex workers and truck drivers (Venkataramana and Sarada 200I). Accurate survey data allowed the Government of India to focus its prevention efforts on very specific communities and states with concentrated epidemics (UNAIDS 2007), like Manipur, Andhra Pradesh, and Karnataka. 
Summary of contribution of evidence to the policy process:

The NFHS-3 findings, in combination with other sources of data (step 3), enabled the government and stakeholders to mount a well-informed and focused policy and programmatic response to their country's HIV/AIDS epidemic (step 4). Rather than overextending themselves deploying resources to address a nonexistent generalized epidemic, the Indian government and donor organizations could focus aid on the most vulnerable populations (step 5). Programming specific to truckers, migrants, and sex workers in particular has been developed, tailored to their specific health risks and needs.

\section{Rwanda}

In the 1980s, Rwanda experienced a dramatic increase in its population as mortality - especially infant mortality - declined, while fertility remained high and highly valued (May et al. 1990). "Demographic entrapment," or the pressure of an exploding population confined to a very small country, became a pressing problem, and is recognized as contributing to the country's recent tumultuous history. In 1993, the year before the genocide, Rwanda's population density was one of the highest in Africa, at 285 people/km2 (Bonneuz 1994). Following the genocide, Rwanda's population grew by 90 percent in 15 years, to 10.6 million in 2010 (Madsen 20II) and intense competition for land and resources continues to present a challenge (Wadhams 2010), as do hunger and poverty, poor sexual and reproductive health, and child survival (International PA 2007).

Although the subject of family planning was especially sensitive after the loss of life in 1994 (Kinzer 2007), it was put back on the agenda after the release of Rwanda 2005 DHS (Solo et al. 2005), which showed a TFR of 6.0, contraceptive prevalence of 10 percent, and unmet need for family planning at 38 percent (Institute National de la Statistique du Rwanda 2006). A RAPID presentation to parliamentarians in May 2005 based on these data put high fertility and rapid population growth into perspective by estimating their current and future impact on education, health, food supply and employment (Abel n.d.). RAPID, developed by the USAID-funded POLICY Project and implemented by the Futures Group, is a computer-based model that allows in-country stakeholders to analyze the effect of population factors on socioeconomic development under different scenarios. Model forecasts are only as good as the data that go into them, and the use of the most recent Rwanda DHS was essential for producing up-to-date conclusions and recommendations from the RAPID model. The
RAPID presentation, based on DHS data, demonstrated the unsustainable way in which families were dividing land into smaller and smaller lots for distribution among children; if fertility levels remained high, subdividing would soon cease to be possible (KI7).

These compelling projections caused Parliamentarians as well as Ministry of Finance officials with budgetary influence to become concerned that high rates of population growth would inhibit the country's poverty reduction efforts (Madsen 20I I). These concerns permeated even the highest level of government; President Kagame himself became an outspoken advocate for unprecedented scale-up of family planning services, declaring the issue "priority number one" in 2007 (Solo 2008). Although Rwanda's first Poverty Reduction Strategy document (2002-2005) after the genocide did not mention family planning, the next document, the Economic Development and Poverty Reduction Strategy (2008-20/2) did. Beginning in 2005, the Government of Rwanda developed a national family planning strategy, created a family planning technical working group, established a population desk at the Ministry of Finance, and has shown exceptional interest in and commitment to demographic and health issues.

The high-level commitment has paid off; an interim DHS in 2007-2008 found a TFR of 5.5 (Asiimwe 20II) and contraceptive prevalence of 24 percent (Ministry of Health, NISR and ICF Macro 2009). The results from the 20I4-2015 DHS were more encouraging still: 48 percent of Rwandan women were found to be using a modern method of contraception and TFR had declined to 4.2 births per woman (National Institute of Statistics of Rwanda, Ministry of Health, and ICF International, 2015).

\section{Summary of contribution of evidence to the policy process:}

Many Rwandans agree that it was President Kagame's prioritization of family planning - felt all the way down to the community level - that moved it into the priority policy position in which it remains (Wadhams 2010). This explicit policy emphasis was catalyzed by the very clear issue identification based on Rwanda DHS 2005 data showing low contraceptive prevalence, high fertility, and high unmet need (step $\mathrm{I})$, and the compelling communication of these data (step 2 and 3 ) to high-level officials who then positioned themselves to address the issue (step 4), with President Kagame as their champion. Through raising awareness, family planning was ultimately incorporated into high level documents leading to improved and more widespread reproductive health service provision (step 5). Subsequent survey data 
provided evidence of increases in family planning use and declining fertility levels (step 6).

\section{Discussion}

Although policy formulation and revision is nonlinear (Yamey 20II), complex, and political (Oliver 2006), the evidence presented in these three case studies illustrates the significant contribution of DHS data at a number of important junctures in the policy process (Table 5). These data can help provide information about the scope of a problem (Malawi, India), highlight a mismatch between health-related needs and desires of a population and the provision of health services (Malawi), support local advocates (Malawi), catalyze high-level political will (Malawi, Rwanda), and improve the efficiency and efficacy of public health policies (India). Based on these case studies, the framework presented in Table 4 is an adaption - given the explicit focus on DHS data - of the various models presented in Table I. More specifically, by employing a cross-case analytic approach, we find, echoing Parsons (1996), evidence is used in issue identification and framing, raising awareness of a problem, setting the agenda and establishing political will, all leading towards formulating or revising policy as well as monitoring and implementation.

Loosely based on the stages heuristic public policy framework (Walt et al 2008) of agenda setting, formulation, implementation and evaluation (Walt 1987), Table 4 presents the framework that best summarizes our results. We find that survey data are most often available temporally prior to policy action, although they may be analyzed, interpreted, compiled, disseminated and translated into digestible nuggets of information at any time during the policy formation process. The use of survey data in advocacy and agenda-setting is particularly important, and consistent with the knowledge-driven model as opposed to the problem-solving, tactical, or interactive models. In low-resource settings in particular, the collection of survey data is infrequently commissioned by policymakers due to its expense and large scale. Thus, the case studies are best understood within the knowledge-driven model rather than the problem-solving model. Finally, Table 5 shows that India does not exemplify a situation in which survey data led to an issue being identified (due to pre-survey international pressure to revise HIV estimates) or a policy being monitored or revised (due to lack of follow-up with further data collection). While the former may be consistent with the problem-solving model, the latter is often an issue in low resource settings; both are noticeable but slight deviations from the proposed framework.
While not entirely evident from the case studies themselves, conversations with Interviewees indicated that one important component of the successful use of high-quality and open access DHS data in policymaking is the participation of in-country institutions (statistical and otherwise), communities and individuals in survey development, data collection, dissemination and use. The DHS are typically planned and guided by a Survey Steering Committee (SSC) comprised of representatives from host country agencies and civil society organizations as well as bilateral and international stakeholders. Each SSC is concerned with the goals and objectives of the survey, policy considerations, and technical issues such as questionnaire content, and meets at key points in the survey planning and dissemination process. This enables policymakers' interests to be better aligned with data and research priorities, which has been recommended in the literature (Hunter 2009).

This attention to coordination during the survey planning stage ensures early and ongoing dialogue between data producers and end-users, increasing the likelihood that survey data will be accepted and utilized by host governments and other stakeholders. Additionally, high levels of in-country statistical and institutional capacity are essential; implementation of the DHS by a local statistical and/or demographic agency helps to ensure country ownership and data relevance. The collection of HIV prevalence data in India, for example, where no nationally representative data source had previously existed, demonstrates the benefits of shared priorities and country ownership in producing high quality local and global estimates of the burden of disease. Finally, it is critical that all interested end-users have access to relevant, timely and accurate survey data in usable formats. In the case of Rwanda, for example, the reporting of low contraceptive prevalence and high fertility levels along with land use data spurred President Kagame and the Government of Rwanda's commitment to family planning.

Finally, we find that during the policy process, survey data can strategically highlight competing priorities as well as areas for synergy. For example, the RAPID presentation in Rwanda highlighted linkages between health, development, sustainability, environment and economic growth, engaging stakeholders with the challenge of high fertility regardless of their backgrounds and vested interests. In fact, although evidence availability and even its use may not always bring about policy change per se, it can at the very least provide ideas and arguments to challenge decision-makers' assumptions. This was particularly apparent in Malawi, where both policymakers and medical practitioners were 
challenged to set aside their preconceived notions about the provision of injectables by non-medical professionals at the community level.

There are several limitations to this study. First, in terms of the study methodology, it would have been very informative to interview government and civil society stakeholders who directly participated in the events described in the case studies. Unfortunately, many of these stakeholders were no longer at their posts and, given limited resources, it was not feasible to track and interview them for this study. Thus, this study was dependent on key informants who were relatively accessible to the investigators (in addition to written documentation of events), and this respondent bias may have resulted in less detailed or nuanced insight than would have been available had the authors reached informants who were closer to the events in-country. While this study does not benefit from either the insight of policymakers directly involved in the events described or direct quotes from interviewees, this is the first illustration, to our knowledge, of the use of survey data in policymaking in the developing country context.

A second limitation is that the interviews were not recorded. As such, there may have been memory lapses that were not bridgeable by the copious notes taken by LBN and RN during the interviews. However, the data were analyzed and the first draft of the manuscript was written within two months of the start of data collection, which should reduce concerns regarding this limitation. A third limitation is that the process of policy development is very slow and often shrouded in mystery and political maneuvering, making documentation a challenge. The highlighted case studies were chosen based in part on the availability of documentation and therefore may represent only one type of policymaking process (i.e. one that is relatively transparent). However, while the case studies presented illustrate only instances of successful use of survey data, this corresponds well to the purpose of this study, which is to describe the use of evidence in the policy process in order to facilitate its further future integration. Finally, we explicitly highlight the use of freely available and nationally representative high-quality DHS data in the policymaking processes in three specific developing countries; the results should not be generalized indiscriminately to other types of data. Further research in this area is needed.

Despite these limitations, we believe the three case studies presented here helpfully highlight the ways in which evidence, and DHS data in particular, has been successfully used to facilitate the efficiency and effectiveness of health policy in low resource settings. It still remains necessary, however, for governments to fully develop and sustain vital http://aps.journals.ac.za registration systems and to conduct population censuses at regular intervals because these data sources allow for administrative identification and enumeration of individuals, which supports their access to services such as healthcare and education. Future research into whether the integration of survey data more generally and/or administrative data in particular into the policy process can be characterized by a trajectory similar to that which is described in this paper would be fruitful. It may also be helpful to empirically investigate instances in which the use of data in the policy process was somehow thwarted in order to learn from failures as well as successes.

\section{Conclusions}

EBHP is an important input into strong health systems, programs and services. This study is intended to illustrate the ways in which DHS data in particular have been integrated in certain instances into the health policy process in low- and middleincome countries. The framework presented here, based on three case studies, can serve as a guide for planning a strategic approach to enhancing the use of survey data in policymaking in low resource contexts. Specifically, we find that some of the most effective ways of supporting this process include using data to inform policymakers about the scope of a health problem, highlighting a lack of access to health services or products, supporting advocacy efforts, and even catalyzing high-level political will leading to policy formation and revision. To bring this about, we argue that it is advisable to partner with local institutions trained in survey and statistical methods during survey development, data collection and dissemination to ensure relevance. High quality and timely data collection are similarly important, and can drastically improve the efficiency and efficacy of public health policies by facilitating their monitoring and evaluation. The use of evidence in health policymaking is highly desirable; we hope this study encourages researchers, policymakers and advocates to learn from past successes and facilitate its future use.

\section{List of Abbreviations:}

UNAIDS: Joint United Nations Programme on HIV/AIDS; SSC: Survey steering committee; EBHP: Evidence-based health policy; DHS: Demographic and Health Surveys; USAID: US Agency for International Development; TFR: Total fertility rate; CPR: Contraceptive prevalence rate; CBDA: community based distribution agents; LBN: first author Laura B. Nolan; RL: second author Rachel Lucas; RHU: Reproductive health unit; $\mathrm{MOH}$ : Ministry of Health; HSA: Health Surveillance 
Assistants; NACO: National AIDS Control Organization; NFHS: National Family and Health.

\section{Competing Interests:}

The authors do not have a commercial or other association that might pose a conflict of interest.

\section{Authors' contributions:}

LBN and RL conducted the interviews and drafted the manuscript. YC, MSF, and JA provided input and comments to the manuscript.

\section{Acknowledgements:}

Views and opinions expressed in this paper are the authors'. They do not necessarily represent

the views and opinions of the US Agency for International Development. During data collection LBN was supported by the Public Health Institute during an internship in the Policy, Evaluation and Communication Division, Office of Population and Reproductive Health, Global Health Bureau, US Agency for International Development. For the writing of this paper, LBN received support from the Eunice Kennedy Shriver National Institute of Child Health and Human Development (grant \#5R24HD047879) and from the National Institutes of Health (grant \#5T32HD007I63).

Table I: Models of the use of evidence in policymaking, adapted from Weiss 1979

\begin{tabular}{|c|c|c|c|c|}
\hline Model & Brief description & Strengths & Weaknesses & $\begin{array}{l}\text { Components } \\
\text { adopted }\end{array}$ \\
\hline $\begin{array}{l}\text { Knowledge- } \\
\text { driven model }\end{array}$ & $\begin{array}{l}\text { Evidence compels action } \\
\text { in a linear sequence, } \\
\text { from development to } \\
\text { application }\end{array}$ & -Simplicity & $\begin{array}{l}\text { - Linearity } \\
\text {-Assumption that } \\
\text { compelling } \\
\text { knowledge already } \\
\text { exists } \\
\end{array}$ & $\begin{array}{l}\text {-Evidence as } \\
\text { coming } \\
\text { temporally prior } \\
\text { to policy action }\end{array}$ \\
\hline $\begin{array}{l}\text { Problem- } \\
\text { solving model }\end{array}$ & $\begin{array}{l}\text { The problem is first } \\
\text { identified and a search or } \\
\text { request for research on } \\
\text { the topic is subsequently } \\
\text { issued }\end{array}$ & $\begin{array}{l}\text {-Simplicity } \\
\\
\text {-Most } \\
\text { realistic/likely }\end{array}$ & $\begin{array}{l}\text {-Linearity } \\
\text {-Assumption of } \\
\text { consensus on goals } \\
\text { between } \\
\text { policymaker and } \\
\text { researcher }\end{array}$ & $\begin{array}{l}\text {-Problem } \\
\text { identification as } \\
\text { central to policy } \\
\text { action }\end{array}$ \\
\hline $\begin{array}{l}\text { Interactive } \\
\text { model }\end{array}$ & $\begin{array}{l}\text { A non-linear process } \\
\text { involving ongoing } \\
\text { interaction between } \\
\text { policymakers and } \\
\text { evidence producers }\end{array}$ & $\begin{array}{l}\text {-Familiar, iterative } \\
\text { learning process }\end{array}$ & $\begin{array}{l}\text {-Idealistic, } \\
\text { unrealistic, unlikely } \\
\text {-Assumes } \\
\text { underlying interest } \\
\text { in research on the } \\
\text { part of policymakers }\end{array}$ & -None \\
\hline Political model & $\begin{array}{l}\text { Evidence is used } \\
\text { selectively by } \\
\text { policymakers to forward } \\
\text { their own agenda }\end{array}$ & $\begin{array}{l}\text {-Realistic } \\
\text {-Allows for } \\
\text { distortion, } \\
\text { misrepresentation } \\
\text { of findings }\end{array}$ & $\begin{array}{l}\text {-Research as } \\
\text { political ammunition } \\
\text { is unattractive }\end{array}$ & $\begin{array}{l}\text {-Political will, } \\
\text { priorities }\end{array}$ \\
\hline Tactical model & $\begin{array}{l}\text { Under pressure for action } \\
\text { on an issue, } \\
\text { policymakers } \\
\text { commission research }\end{array}$ & $\begin{array}{l}\text {-Accommodates } \\
\text { possibility that } \\
\text { ongoing research is } \\
\text { "used" as a stalling } \\
\text { technique (not for } \\
\text { content) } \\
\end{array}$ & $\begin{array}{l}\text {-Ignores research } \\
\text { content, findings }\end{array}$ & -None \\
\hline $\begin{array}{l}\text { Enlightenment } \\
\text { model }\end{array}$ & $\begin{array}{l}\text { Research over time } \\
\text { blends into established } \\
\text { insights, theories and } \\
\text { concepts, then utilized in } \\
\text { policymaking }\end{array}$ & $\begin{array}{l}\text {-Emphasizes } \\
\text { importance of time } \\
\text {-Research need not } \\
\text { be aligned with } \\
\text { policymakers' } \\
\text { goals }\end{array}$ & -Idealistic & -None \\
\hline
\end{tabular}


Table 2: Demographic and Health Surveys conducted in Case Study Countries

\begin{tabular}{|lll|}
\hline Country & DHS Survey Dates & Implementing Organization \\
\hline Malawi & $1992,2000,2004,2010,2015-2016$ & The National Statistical Office \\
\hline India & $1992 / 3,1989 / 90,2005 / 6$ & International Institute of Population Sciences (IIPS) \\
\hline Rwanda & $\begin{array}{l}1992,2000,2005,2010 \\
\text { (Interim DHS in 2007/08), 2014- } \\
2015\end{array}$ & $\begin{array}{l}\text { Institute National de la Statistique/ Ministère des Finances } \\
\text { et de la Planification Economique }\end{array}$ \\
\hline
\end{tabular}

Table 3: Study participant sector and role

\begin{tabular}{|c|c|c|c|c|}
\hline Participant & Sector and role & Contact method & Interview method & Case study \\
\hline KI-1 & US Government & In person & In person & Malawi \\
\hline KI-2 & Non-governmental organization & Phone & Phone & Malawi \\
\hline KI-3 & Foundation & Email & Phone & Malawi \\
\hline KI-4 & US Government & In person & In person & Malawi \\
\hline KI-5 & Survey implementor & Email & In person & India \\
\hline KI-6 & Survey implementor & Email & In person & India \\
\hline KI-7 & US Government & In person & In person & Rwanda \\
\hline I-1 & Survey implementor & Email & In person & NA \\
\hline I-2 & US Government & Email & In person & NA \\
\hline I-3 & Survey implementor & Email & In person & NA \\
\hline I-4 & US Government & In person & In person & NA \\
\hline I-5 & Survey implementor & Email & In person & NA \\
\hline I-6 & Think tank & Email & In person & NA \\
\hline I-7 & Survey implementor & Email & In person & NA \\
\hline I-8 & Survey implementor & In person & In person & NA \\
\hline I-9 & For profit & Email & Phone & NA \\
\hline I-10 & Non-governmental organization & Email & In person & NA \\
\hline I-11 & US Government & In person & In person & NA \\
\hline I-12 & Survey implementor & Email & In person & NA \\
\hline I-13 & Survey implementor & Email & In person & NA \\
\hline I-14 & US Government & In person & In person & NA \\
\hline I-15 & Survey implementor & Email & In person & NA \\
\hline \multirow[t]{3}{*}{ Total } & 22 & & & \\
\hline & $7 \mathrm{KIs}$ & & & \\
\hline & 15 Is & & & \\
\hline
\end{tabular}

$\mathrm{KI}=$ Key Informant (direct information on case studies provided)

$\mathrm{I}=$ Informant (initial/indirect information provided)

$\mathrm{NA}=$ Not applicable; these were indirect informants and thus not responsible for material found exclusively in one of the case studies

Table 4: Proposed model for use of survey data in developing country context based on the three case studies - entry points and contribution

\section{Step in policy/decision-making process}

\section{1) Issue identification}

Issue identification (step 1) can lead to dialogue and advocacy actions, such as issue framing and agenda-setting (step 2) (Monroe 1995).

\section{2) Issue framed, advocated for}

With appropriate issue framing and agenda-setting (step 2), awareness to "enable the policy environment" (Gribble 2010) can be raised among key groups, including government and ministry officials, civil society, bi- and multi-lateral organizations, public

\section{Contribution of survey} data/evidence

1) Identify affected, vulnerable or at risk populations; estimate issue severity

2) Estimate options for action; estimate costs of inaction; model impact on equity 
health practitioners and researchers (step 3).

\section{3) Awareness raised}

Political will and buy-in must then be secured, with involvement of at least one high-level champion being a critical element of success (step 4).

\section{4) Political will established, agenda set}

These activities - when successful - can result in the drafting, consultation or review of a decision, policy, law or regulation, and if necessary, resource allocation (step 5).

\section{5) Policy formulated, revised}

Policy implementation (or changes to an existing policy) ideally follows, as does the continuous use of data for subsequent monitoring and issue-identification (step 6).

3) Presentation to stakeholders, media

4) High-level dissemination and agenda-setting; cost-

effectiveness studies; leveraging of competing interests

5) Recommendation on targeted groups, resource allocation; discussion of possible unintended consequences

6) Scrutinize roll-out and impact

6) Policy monitoring, implementation

6) Scrutinize roll-out and impact

Table 5: Data use in each case study by step in policy/decision-making process

\begin{tabular}{|c|c|c|c|c|c|c|}
\hline Case Study & \multicolumn{7}{|c|}{ Policy/decision making step } \\
& $\begin{array}{c}\text { 1) Issue } \\
\text { identified }\end{array}$ & $\begin{array}{c}\text { 2) Issue } \\
\text { framed, } \\
\text { advocated }\end{array}$ & $\begin{array}{c}\text { 3) Awareness } \\
\text { raised }\end{array}$ & $\begin{array}{c}\text { (4) Political will } \\
\text { established, } \\
\text { agenda set }\end{array}$ & $\begin{array}{c}\text { (5) Policy } \\
\text { formulated, } \\
\text { revised }\end{array}$ & $\begin{array}{c}\text { (6) Policy } \\
\text { monitored, } \\
\text { implemented }\end{array}$ \\
\hline Malawi & + & + & + & + & + & + \\
\hline India & & & + & + & + & + \\
\hline Rwanda & + & + & + & + & + & + \\
\hline
\end{tabular}

Key: $+=$ DHS data used at this step; blank = DHS data not used at this step or step not relevant to the case study

\section{REFERENCES}

Abel, E. RAPID: Computer Programs for Examining Socioeconomic Impacts of Population Growth. USAID | Health Policy Initiative, Task Order I, no date.

AbouZahr, C., Adjei, S., Kanchanachitra, C. (2007). From data to policy: good practices and cautionary tales. The Lancet. 369 (9566), 1039-46.

Asiimwe A. (20I I). Rwanda: A sweet pill in the health sector. Available from: http://allafrica.com/stories/20I I06230639.html [Accessed on December 16, 2016].

Behague, D., Tawiah C, Rosato M, Some T, Morrison J. (2009) Evidence-based policy-making: the implications of globally-applicable research for context-specific problem-solving in developing countries. Social Science \& Medicine. 69(10): 1539-46.

Birnbaum, R. (2000). Policy scholars are from Venus; policy makers are from Mars. The Review of Higher Education. 23 (2).

Boerma, J., Stansfield, S. (2007). Health statistics now: are we making the right investments? Lancet. 369 (9563), 779-86.

Bonneux, L. (1994). Rwanda: a case of demographic entrapment. Lancet. 344 (8938), I689-90.
Brownson, R., Chiriqui, J., Stamatakis, K. (2009). Understanding Evidence-Based Public Health Policy. American Journal of Public Health. 99 (9).

Buse, K., Mays, N., G W. (2005). Making Health Policy. Series UPH, editor: Open University Press.

Campbell, S., Benita, S., Coates, E., Davies, P., Penn, G. (2007). Analysis for policy: Evidence-based policy in practice. London: Government Social Research Unit.

Chhabra, S. (2008). National Family and Health Survey (NFHS-3): Policy and Program Implications.

Clemens, M., Demombynes, G. (20/3). The New Transparency in Development Economics: Lessons from the Millennium Villages controversy. World Economics. 14(4):77-97.

Cohen, J. (2007). HIV/AIDS: India Slashes Estimate of HIV-Infected People. Science. 3 I 7 (5835), I79-8I. doi: 10.1 I 26/science.317.5835.179.

Corbin, J SA. (2008). Basics of Qualitative Research: Techniques and Procedures for Developing Grounded Theory: Sage Publications.

Galea, S., Riddle, M., Kaplan, G.A. (20I0). Causal thinking and complex system approaches in epidemiology. International Journal of Epidemiology. 39 (I), 97-I06. 
Ghosh, P., Arah, O., Talukdar, A., Sur, D., Babu, G., Sengupta, P., et al. (20II). Factors associated with HIV infection among Indian women. International journal of STD \& AIDS. 22 (3), | 140-5.

Gilson, L, Raphaely, N. (2008). The terrain of health policy analysis in low and middle income countries: a review of published literature 19942007. Health policy and planning. 23 (5), 294-307.

Hanney, S., Gonzalez-Block, M., Buxton, M., Kogan, M. (2003). The utilisation of health research in policy-making: concepts, examples and methods of assessment. Health research policy and systems / BioMed Central. I (I), 2.

Haub, C., Kent, M. (2008). World Population Data Sheet. Washington, D.C.: Population Reference Bureau

Health Policy Initiative Task Order I. 20I0. The Art of Moving From Policy to Action: Lessons learned from the USAID | Health Policy Initiative (20052010). Futures Group: Washington, D.C.

Hunter, D.J. (2009). Relationship between evidence and policy: A case of evidence-based policy or policy-based evidence? Public Health. I 23 (9), 583-6.

Institute National de la Statistique du Rwanda (INSR) and ORC Macro. (2006). Rwanda Demographic and Health Survey 2005. Chapter 5: Family Planning. Calverton, MD: Institute National de la Statistique du Rwanda (INSR) and ORC Macro.

International Institute for Population Sciences (IIPS) and Macro International. (2007). National Family and Health Survey (NFHS-3), 2005-2006: Volume I: Chater 12: HIV prevalence. Mumbai, India: International Institute for Population Sciences (IIPS) and Macro International.

International PA. (2007). Rwanda justly prioritizes family planning, success will come if programs are voluntary. Available from: http://populationaction.org/blog/2007/02/20/rwan da-justly-prioritizes-family-planning-success-willcome-if-programs-are-voluntary/. [Accessed January II, 20I4]

Jiang, F., Zhang, J., Shen, X. (20/3). Towards evidence-based public health policy in China. Lancet. 38I (9882), I962-4.

Kadiyala, S., Barnett, T. (2004). AIDS in India: Disaster in the making. Political and Economy Weekly. 39 (19), 1888-92.

Kates, J., Martin, A., Carbaugh, A. (2006). HIV/AIDS Fact SheetL HIV/AIDS in India. Menlo Park, CA: Kaiser Family Foundation.

Kinzer, S. (2007). After So Many Deaths, Too Many Births. Available from: http://www.nytimes.com/2007/02/I I/weekinrevie w/l l kinzer.html?_r=0. [Accessed December 16, 2016].
Lewin, S., Bosch-Capblanch, X., Oliver, S., Akl, E.A., Vist, G.E., Lavis, J.N., et al. (20/2). Guidance for evidence-informed policies about health systems: assessing how much confidence to place in the research evidence. PLoS medicine. 9 (3).

Madsen, E.L. (20II). Rwanda: Dramatic Uptake in Contraceptive use Spurs Unprecedented Fertility Decline. Available from: http://www.newsecuritybeat.org/20 I I/I I/building -commitment-to-family-planning-

rwanda/\#.UtHrVp5dWDk. [Accessed December 16, 2016].

Malawi National Statistical Office and ICF Macro. (20II). 2010 Malawi Demographic and Health Survey: Key findinds. Calverton, MD: Malawi National Statistical Office, ICF Macro.

Malarcher, S. (2009). A Review of the Evidence Developed for a Technical Consultation on Expanding Access to Injectable Contraception. Geneva, Swizerland: Prepared for a Technical Consultation coordinated by the World Health Organization, U.S. Agency for International Development, and Family Health International.

May, J.F., Mukamanzi, M., Vekemans, M. (1990). Family planning in Rwanda: status and prospects. Stud Fam Plann. 2I (I), 20-32.

Milani, C.R.S. (2005). Evidence-based policy research: critical review of some international programmes on relationships between social science research and policy-making. UNESCO

Ministry of Health Reproductive Health Unit and Health Policy Initiative. (2008). Meeting Proceedings. Community-Based Distribution of DMPA: Stakeholders' Meeding. Crossroads Hotel, Lilongwe, Malawi.

Ministry of Health $(\mathrm{MOH})$ [Rwanda] and National Institute of Statistics of Rwanda (NISR) and ICF Macro. (2009). Interim Demographic and Health Survey 2007-2008. Chapter 5: Family Planning. Calverton, MD: Ministry of Health (MOH) [Rwanda] and National Institute of Statistics of Rwanda (NISR) and ICF Macro.

Moat, K.A., Lavis, J.N. (20I3). 10 best resources for evidence-informed health policy making. Health policy and planning. 28 (2), 2I5-8.

Morgan, G. (2010). Evidence-based health policy: A preliminary systematic review. Health Education Journal. 69 (43), 43-7.

National AIDS Control Organization. (2006). HIV/AIDS epidemiologica surveyllance \& estimation report for the year 2005. New Delhi, India.

National Institute of Statistics of Rwanda (NISR) [Rwanda], Ministry of Health (MOH) [Rwanda], and ICF International. 20I5. Rwanda Demographic and 
Health Survey 20I4-I5. Rockville, Maryland, USA: Short Fabic M., Choi, Y., Bird, S. (20I2). A systematic $\mathrm{NISR}, \mathrm{MOH}$, and ICF International.

National Statistical Office (NSO) [Malawi] and ICF International. (2016). Malawi Demographic and review of Demographic and Health Surveys: data availability and utilization for research. Bulletin of the Health Survey 2015-16: Key Indicators Report. Solo, J., Jacobstein, R., Malema, D. (2005). Malawi case Zomba, Malawi, and Rockville, Maryland, USA. NSO study: Choice, not change. A Repositioning Family and ICF International.

Oliver TR. (2006). The politics of public health policy. Annual review of public health. 27:195-233. Planning Case Study. New York, NY: Engender Health/ACQUIRE Project

Orem, J.N., Mafihiri, D.K., Marchal, B., Ssengooba, F., Macq, J., Criel, B. (20|3). Research, evidence and Solo, J. (2008). Family Planning in Rwanda: How a taboo subject became priority number one. IntraHealth International.

policymaking: the perspectives of policy actors on Sutcliff, S., Court, J. (2005). Evidence-Based improving uptake of evidence in health policy Policymaking: What is it? How does it work? What development and implementation in Uganda. BMC Public Health. 12 (109). doi: I0.II86/I47/-2458-I2109.

Pandey, A., Reddy, D.C.S., Thomas, M. (2008). What Lies behind the Fall in the HIV Population in India? Economic and Political Weekly. 43 (52), I5-7. relevance for developing countries? Overseas Development Institute.

UNAIDS. (2007). Call excerpt. Available from: http://data.unaids.org/Pub/informationnote/2007/200 70625_india_call_excerpts_en.pdf. [Accessed December 16, 2016].

Pandey, A., Reddy, D.C., Ghys, P.D., Thomas, M., Sahu, UNAIDS. (2006). Report on the global AIDS epidemic. D., Bhattacharya, M., et al. (2009). Improved UNAIDS. (2007). Q+A on India's revised AIDS estimates of India's HIV burden in 2006. The Indian journal of medical research. 129 (I), 50-8.

Parsons, W. (1995). Public Policy: An introduction to theory and practice of policy analysis. Elgar AE, editor estimates $2007 . \quad$ Available from: http://www.aidsdatahub.org/sites/default/files/docum ents/unaids_India_external_QA.pdf.pdf. [Accessed December 16, 2016].

Philpott, A., Maher, D., Grosskurth, H. (2002). Venkataraman, C.B., Sarada, P.V. (200I). Extent and Translating HIV/AIDS research findings into policy: speed of spread of HIV infection in India through the lessons from a case study of 'the Mwanza trial'. Health policy and planning. 17 (2), I96-20I. commercial sex networks: a perspective. Tropical medicine \& international health. 6 ( | 2), |040-6|.

Rao, J.V.R.P., Ganguly, N.K., Mehendale, S.M., Bollinger, Wadhams, N. (2010). Progress in Rwanda's drive to slow R.C. (2004). India's response to the HIV epidemic. population growth. The Lancet. 376 (9735), 8I-2. The Lancet. 364 (9442), I 296-7. Walt, G. (1987). Health Policy: An Introduction to

Richardson, F., Chirwa, M., Fahnestock, M., Bishop, M., Process and Power. London: Zed Books.

Emmart, P., McHenry, B. (2009). Community-based Walt, G., Gilson, L. (1994). Reforming the health sector Distribution of Injectable Contraceptives in Malawi. in developing countries: the central role of policy Washington, D.C.: Futures Group. analysis. Health policy and planning. 9 (4), 353-70.

Rychetnik, L., Bauman, A., Laws, R., King, L., Rissel, C., Walt, G., Shiffman, J., Schneider, H., Murray, S.F., Nutbeam, D., et al. (2012). Translating research for evidence-based public health: key concepts and future directions. Journal of epidemiology and community health. 66 (12), II87-92. Brugha, R., Gilson L. (2008). 'Doing' health policy analysis: methodological and conceptual reflections and challenges. Health policy and planning. 23 (5), 308-.

Segone, M., Pron, N., editors. (2008). The Role of Weiss, C.H.. (1979). The Many Meanings of Research Statistics in Evidence-Based Policy Making. United Nations Statistical Commission and Economic 3I.

Commission for Europe Conference of European Yamey, G, Feachem, R. (20lI). Evidence-based Statisticians Geneva, $\mathrm{CH}$. policymaking in global health - the payoffs and pitfalls.

Shaxson, L. (2006). Is your evidence robust enough? Evidence-Based Medicine. I6(4):97-9.

Questions for policy makers and practitioners. Yin, R.K. (2003). Case Study Research: Sage Publications; Brokering Digest Issue \# 16. 2003. 